\title{
A physician workforce planning model applied to Canadian anesthesiology: assessment of needs
} [Un modèle de planification des effectifs médicaux appliqué à l'anesthésiologie canadienne: évaluation des besoins]

Robert J. Byrick MD FRCPC, ${ }^{*}$ Douglas Craig MD FRCPC, $†$ Franco Carli MD MPHIL FRCA

Purpose: A human resource planning model for anesthesiology is described.

Methods: The model uses 'per capita' expenditure for anesthesiologists in Quebec, as a measure of clinical services provided to different age/gender groups. The future demand for anesthesia services is calculated as the product of 'per capita' expenditure and the population projections to a future date. Future demand was converted into full-time equivalent (FTE) providers required, by dividing by the annual 'units of service' optimally delivered by one FTE anesthesiologist. The pattern of age/gender (demographic) consumption of anesthesia services in Quebec was compared with data from Ontario to validate its use in a planning model. The model was then applied to all provinces and territories.

Results: The 'per capita' expenditures on anesthesia services in Quebec and Ontario showed a regular pattern. Using the model, the estimated 1999 demand for FTE anesthesiologists to provide clinical services in Quebec is 546 and 669 for 2016 . When nonclinical demands were included, we estimated that Quebec's total demand will increase to approximately 730 FTEs in 2016. Similar estimates are made for all provinces. The population increase anticipated is $17.9 \%$ but the increase in FTE demand in Canada is $30.9 \%$.

Conclusion: The model showed that the cause of the increased FTE demand for anesthesiologists is a combination of increased population and its demographic composition. The relative impact of each of these factors varies in different provinces. Effective specialty-specific planning models can be designed but they need ongoing committed resources and personnel for their usefulness to be maximized.

Objectif : Décrire un modèle de planification des ressources humaines pour l'anesthésiologie.

Méthode : Le modèle utilise les dépenses "par habitant" pour les anesthésiologistes du Québec comme mesure des services cliniques fournis aux groupes d'âge et de sexe différents. La demande de futurs services d'anesthésie est calculée comme le produit des dépenses "par habitant" et des projections de population à une date ultérieure. La demande future a été convertie en dispensateurs nécessaires en équivalent temps plein (ETP) en divisant par les "unités de service" annuelles fournies de façon optimale par l'ETP d'un anesthésiologiste. Le modèle de consommation de services d'anesthésie selon l'âge/le sexe (données démographiques) au Québec a été comparé aux données provenant d'Ontario afin de valider son utilisation dans un modèle de planification. Le modèle a été ensuite appliqué à toutes les provinces et territoires.

Résultats : Les dépenses "par habitant" des services d'anesthésie au Québec et en Ontario affichent une forme régulière. Avec ce modèle, la demande d'anesthésiologistes en ETP au Québec est estimée à 546 pour 1999 et à 669 pour 2016. Quand nous ajoutons les demandes non cliniques, nous estimons que la demande totale du Québec va augmenter à 730 ETP environ en 2016. Des estimations semblables ont été faites pour toutes les provinces. L'accroissement de la population prévu est de 17,9\%, mais celui de la demande en ETP au Canada est de 30,9\%.

Conclusion : Le modèle a montré que la cause de l'augmentation de la demande en ETP pour les anesthésiologistes est une combinaison de l'accroissement de la population et de sa composition démographique. L'impact relatif de chacun de ces facteurs varie d'une province à l'autre. Les modèles de planification efficaces, spécifiques à une spécialité, peuvent être élaborés, mais exigent l'utilisation maximale de ressources permanentes et de personnes engagées.

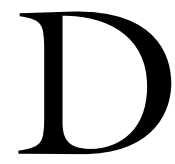

URING the last decade several western countries, including Canada, reported shortages of physicians delivering anesthesia services. ${ }^{1-3}$ In Canada, the shortage has been addressed both nationally and provincially on an ad hoc, interim basis. The Association of Canadian

From the Departments of Anaesthesia, University of Toronto, ${ }^{*}$ University of Manitoba, $\uparrow$ and McGill University $\ddagger$ Address correspondence to: Dr. Robert J. Byrick, Department of Anaesthesia, University of Toronto, Room 132, FitzGerald Building,

150 College Street, Toronto, Ontario M5S 3E2, Canada. Phone: 416-978-4306; Fax: 416-978-2408; E-mail: robert.byrick@utoronto.ca Accepted for publication March 28, 2002.

Revision accepted May 30, 2002. 
University Departments of Anesthesia (ACUDA) commissioned a study to assess future requirements, with sufficient lead-time to adopt policies directed towards ensuring an adequate future supply of anesthesiologists. ${ }^{\mathrm{A}}$

This report is the first of two publications derived from the comprehensive human resource planning (HRP) model designed specifically for the specialty of anesthesia. ${ }^{4}$ This HRP model uses an innovative methodology that includes a means of quantifying the 'units of service' delivered. The full report is available at the ACUDA website (http://www.anesthesia.org /acuda/en/ryten.html). Unlike other HRP models, ${ }^{1-3,5}$ this methodology includes population demographics (e.g., age and gender) in the calculation of the required number of full-time equivalent (FTE) anesthesiologists. It is widely recognized that consumption of health care resources varies with patient age and gender, yet, most planning models do not include the influence of these factors in quantifying the future demand for anesthesia providers. ${ }^{1,3,5}$

The HRP model was based on an analysis of billing data from Quebec, which was used to estimate the 'per capita' consumption of anesthesia services by each demographic group. In this article, we provide an overview of the model and use data derived from the report $^{4}$ to illustrate its use to estimate the future demand for anesthesiologists in each province.

\section{Methods}

\section{Rationale and description of model}

The underlying rationale for this HRP model, developed by E. Ryten, ${ }^{4}$ differs from general physician workforce models in that the variables included specifically deal with the demand for health care services delivered almost exclusively by anesthesiologists. The model consists of two major segments, one that calculates the future demand for anesthesia services and another that anticipates future supply under a variety of conditions. This article deals with segment 1 , the future demand for anesthesia services in Canada.

\section{Data sources}

The billing agency of the province of Quebec, the Régie de l'assurance maladie du Québec, (RAMQ) maintains a data system that records all acts/health care services for which a fee is paid. The record includes the specific medical act that was performed, the dollar value paid for the act, the physician who

\footnotetext{
A Anesthesiologist refers to a physician who has Royal College of Physicians and Surgeons of Canada (RCPSC) certification in anesthesiology or is recognized as a specialist in his/her own province.
}

performed it and demographic data on the patient to whom the service was delivered. It is the inclusion of the patient demography along with the other information that makes RAMQ a valuable data source for health services research. The RAMQ research department prepared statistics under contract to describe what services anesthesiologists provide, billings for these services and the demographic characteristics of the patients served. These data covered all anesthesia services delivered over an entire year (1998-99). All services were included even if non-anesthesiologists delivered them. From the database, members of the Association des Anesthésiologistes du Québec (AAQ) classified more than 2,000 anesthesia services into analytically useful groupings. The classification was designed to enable a detailed measurement of the work of anesthesiologists and thus, distinguish between the surgical and non-surgical activities. This permitted an analysis of changing rates of utilization for specific services. Total expenditures on these anesthesia services for patients in each of 18 age/gender categories were used as a proxy for the 'units of service' provided for each group. The validity of using dollar values as a measure of 'units of service' is only possible if the time spent in providing equivalent services is comparable. Because time is an essential element of the "resources" used for anesthesia billings, this seemed warranted.

Statistics Canada provided population estimates for each province. These population estimates projected the age and gender (demographic) characteristics of the population for 2016. The Statistics Canada projections ${ }^{\mathrm{B}}$ assumed general rates of immigration, emigration, internal migration between provinces, birth and death. These projections included four potential population scenarios for each province: a low, medium and two high growth scenarios. Analyses based on all projections are available in the full report, ${ }^{4}$ however in this article, we detail only one growth scenario for the year 2016 (termed the "high 2" projection in full report). This scenario was chosen as it seems representative of reasonable growth-rate projection, although all projections may be unreasonably low. Interested readers are referred to the full report for other scenario options. ${ }^{4}$

\section{Validation of the model}

Comprehensive billing data were also obtained from the database of the Ontario Health Insurance Plan

\footnotetext{
B Statistics Canada. Estimates: vital statistics and population estimates, demography division. Projections: population projections section, demography division, September 1999.
} 
(OHIP) through the assistance of the Ontario Medical Association. The analysis of OHIP billing data (1998-99) was undertaken to establish total expenditures on anesthesia services by physicians who were recognized as specialists. The Ontario data, therefore, includes only specialist anesthesiologist billings, whereas the RAMQ data reports expenditures for all anesthesia services in Quebec. For both Ontario and Quebec (1998-99), the 'per capita' expenditure on anesthesia services for each age/gender group was calculated by dividing the total annual expenditure for that age/gender group by the total number of people in the group. If the pattern of 'per capita' expenditure by age and gender groups was similar in these two provinces, we reasoned that a regular pattern of utilization had been established and the model could be generally applicable to other provinces.

\section{Calculation of 'demand' for anesthesia services}

We calculate the future 'demand' for anesthesia services by using the 'per capita' utilization of anesthesia services, derived from 1999 RAMQ data. This 'per capita' expenditure reflects the average consumption of clinical anesthesia services by persons in each age/gender category. By multiplying the average 'per capita' expenditure on anesthesia services by the estimated number of people in each age/gender cohort at a future date (e.g., 2016), we calculate a "demand" for anesthesia services at that time. It is important to emphasize that these projections do not estimate the future costs for anesthesia services, which may vary with many factors. For the purposes of this HRP model, the expenditures on anesthesia services represent the 'units of service' provided for each demographic group.

The estimated 'demand' for anesthesia services in 2016 is calculated for each age/gender group in each province by multiplying the 'per capita' units of service (1998-99) by the number of people projected to be in each demographic group using the demographic estimates obtained from Statistics Canada. ${ }^{\mathrm{B}}$ The sum of the calculated 'units of demand' for all age/gender groups estimates the total for 2016. This 'demand' for anesthesia services may be met by providers in that province or by anesthesiologists elsewhere in the region. Also, these age/gender 'per capita' expenditures include only services delivered under the terms of the fee-for-service billing system. Services delivered outside this system would be in addition. One assumption in the model is that the proportion of services delivered outside the provincial health care system will remain stable.

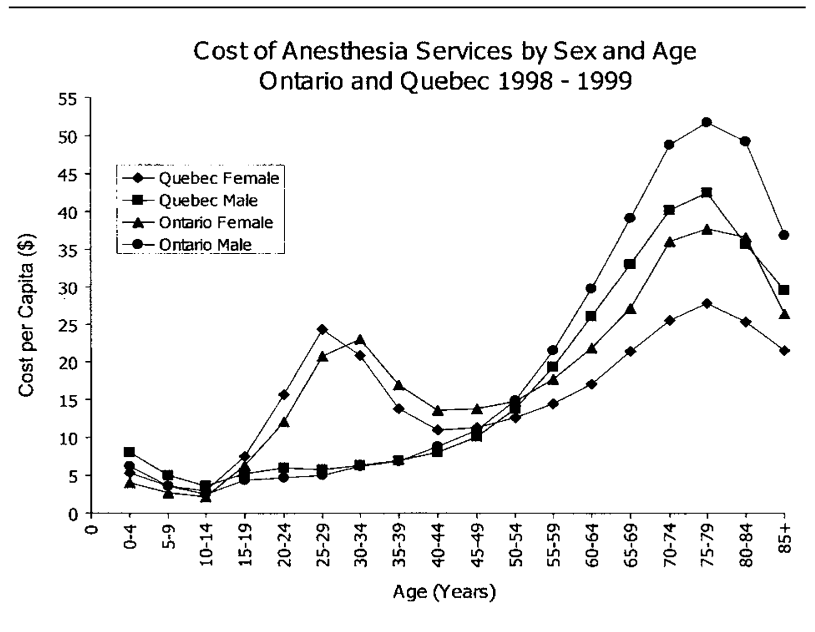

FIGURE Cost of anesthesia services by sex and age for Ontario and Quebec 1998-1999.

\section{Number of FTE anesthesiologists required}

After calculating the total annual 'units of demand' for anesthesia services required by the population of each province in 1999 and 2016, it was necessary to convert this calculated value into the number of FTE anesthesiologists required to provide the service. If the 'units of service' (expenditures) are considered a 'proxy' measurement for the total time spent providing clinical anesthesia services, the number of anesthesiologists needed to deliver these services can be estimated. Discussions with the AAQ provided information that was used to equate one FTE anesthesiologist's workload with a defined amount of billings in 1998-99. It should be emphasized that this number is based on the tariffs prevailing in Quebec in 1998-99. Only if we use the 'per capita' expenditures on anesthesia services from Quebec can we use this conversion factor elsewhere. The definition of one FTE was based on a consensus established by the consultant (E.R.) after discussions with one of the authors (F.C.) that an income around the $75^{\text {th }}$ percentile of all anesthesiologists in Quebec would provide sufficient workload for a full and varied practice, but not so much work that overwork would lead to professional dissatisfaction. After discussions with the executive of the AAQ, a consensus was reached that this represented the billings of an anesthesiologist working approximately 180-200 days per year (1999). Therefore, to estimate the FTE equivalent for all provinces, we applied the rate of conversion (one full-time, full-year anesthesiologist $=175,000$ units of demand) for estimating the FTE equivalent for all provinces. 
The number of FTE anesthesiologists required for clinical service in each province was calculated by dividing the total 'units of demand' for each province by the conversion rate for one FTE anesthesiologist (175,000 units/year). This was done for 1998-99 and 2016. These estimates calculate the number of FTE anesthesiologists required for provision of clinical service and ignore the number required for administrative and academic roles.

\section{Estimation of non-clinical requirements}

In the absence of direct current data, the results from the 1995 Royal College of Physicians and Surgeons of Canada (RCPSC) Specialty Physician Workforce Study ${ }^{\mathrm{C}}$ were re-examined to estimate the number of anesthesiologists involved in non-clinical activities. Adjustments were made to account for non-responders. Of the 2,119 anesthesia certificants who received a questionnaire, 1,558 (73.5\%) provided analysable responses. Since $15.2 \%$ of the non-responders were believed to be professionally inactive in Canada, they were eliminated from the analysis, producing an adjusted response rate of $76.6 \%$. Hours of work data provided by 1,395 responders were used to estimate the hours of work for all active certificants. Adjustments were made to the 1995 study data to match the 1999 and 2016 service volume data (see results for details).

\section{Results \\ Quebec utilization of anesthesia services: by age and by sex}

The RAMQ billing data was used to calculate the 'per capita' expenditure on anesthesia services in Quebec. The 'per capita' expenditure varied substantially for different age and gender components of the population in 1998-99 (Figure). Boys and girls aged 10-14 $\mathrm{yr}$ had the lowest utilization of anesthesia services, $\$ 2.90$ 'per capita' for girls and $\$ 3.56$ for boys. The highest utilization was by men aged 75-79, for whom the 'per capita' cost was $\$ 42.52$. For women, the childbearing years were associated with an increase in the use of anesthesia services in conjunction with surgical and non-surgical childbirth, abortion, sterilization and reproductive healthcare services. Among the older age groups, the consumption was higher on average for men than for women (Figure). Table I shows the 'per capita' expenditure on anesthesia ser-

1995 RCPSC Specialty Physician Workforce Study. Royal College of Physicians and Surgeons of Canada. Ottawa, Ontario. May, 1996. vices (termed units of demand 'per capita' in 1999), the population of Quebec and the estimated demand for anesthesia services in both 1999 and 2016. From these data (Table I), we calculate the number of FTE anesthesiologists required to provide clinical service in Quebec. In 1999, the total expenditure on anesthesia services was $\$ 95,540,084$. Therefore, the number of FTE anesthesiologists needed was 546 $(95,540,084 / 175,000)$.

Utilization of anesthesia services in Ontario and Quebec The Figure also shows the annual 'per capita' expenditure on anesthesia services (1998-99) calculated from the Ontario (OHIP) health care records, as well as the 'per capita' expenditure from Quebec. The lowest 'per capita' expenditures on anesthesia services in Ontario was found for boys and girls (aged 10-14). In both provinces, the same bi-modal pattern of 'per capita' expenditures for women was demonstrated. By age 55-59, males in both provinces increased 'per capita' expenditure on anesthesia services to values greater than females. From these data, family physicians accounted for $8.8 \%$ of the 1998-99 anesthesia billings in Ontario, compared with an estimated 4\% for family practitioners in Quebec.

\section{Projected demand for clinical anesthesia services (2016) for Quebec}

We applied 1998-99 'per capita' expenditure on anesthesia services (Figure, Table I) to estimate the utilization for the projected population of Quebec in 2016. Table I shows the population distribution in 1998-99 and one projection for the year 2016. Table I also shows the calculated demand for anesthesia services consumed by each age and gender group in 1998-99 and 2016 using the model. These data show the aging population and the impact of differential rates of consumption of services by age. Assuming that one FTE anesthesiologist's workload is equivalent to 175,000 units of service per year, we estimate that the need for clinical anesthesiologists for 2016 will be 669 FTEs $(117,053,573 / 175,000)$.

\section{Canada's projected demand for clinical anesthesia ser- vices in 2016}

Since the 'per capita' expenditure on anesthesia services in Ontario revealed a pattern essentially similar to that in Quebec (Figure), we applied the model to calculate future demand in each of the other provinces and the territories. Quebec (RAMQ) data were chosen since these estimates were lower than Ontario's and represented total expenditure on anesthesia services (including family practitioners). For each 
TABLE I Population and estimated demand for anesthesia services in 1999 and 2016

\begin{tabular}{|c|c|c|c|c|c|}
\hline $\begin{array}{l}\text { Male popul } \\
\text { Age } \\
(y r)\end{array}$ & $\begin{array}{l}\text { 'per capita' } \\
\text { units of demand }\end{array}$ & $\begin{array}{l}\text { Quebec population } \\
\text { projection (1999) }\end{array}$ & $\begin{array}{l}\text { Quebec population } \\
\text { projection (2016) }\end{array}$ & $\begin{array}{l}\text { Estimated 'units of } \\
\text { demand' (1999) }\end{array}$ & $\begin{array}{l}\text { Estimated 'units of } \\
\text { demand' (2016) }\end{array}$ \\
\hline $0-4$ & 8.06 & 210,178 & 212,318 & $1,694,035$ & $1,711,283$ \\
\hline $5-9$ & 5.01 & 246,120 & 211,115 & $1,233,061$ & $1,057,686$ \\
\hline $10-14$ & 3.56 & 228,769 & 210,811 & 814,418 & 750,487 \\
\hline $15-19$ & 5.27 & 249,568 & 218,340 & $1,315,223$ & $1,150,652$ \\
\hline $20-24$ & 5.95 & 254,468 & 256,335 & $1,514,085$ & $1,525,193$ \\
\hline $25-29$ & 5.71 & 242,813 & 259,008 & $1,386,462$ & $1,478,936$ \\
\hline $30-34$ & 6.31 & 279,159 & 262,809 & $1,761,493$ & $1,658,325$ \\
\hline $35-39$ & 6.97 & 331,798 & 280,392 & $2,312,632$ & $1,954,332$ \\
\hline $40-44$ & 8.08 & 323,276 & 265,480 & $2,612,070$ & $2,145,078$ \\
\hline $45-49$ & 10.11 & 282,915 & 269,878 & $2,860,271$ & $2,728,467$ \\
\hline $50-54$ & 13.79 & 249,768 & 316,981 & $3,444,301$ & $4,371,168$ \\
\hline $55-59$ & 19.40 & 195,353 & 315,359 & $3,789,848$ & $6,117,965$ \\
\hline $60-64$ & 26.12 & 151,225 & 270,968 & $3,949,997$ & $7,077,684$ \\
\hline $65-69$ & 33.02 & 136,114 & 223,801 & $4,494,484$ & $7,389,909$ \\
\hline $70-74$ & 40.22 & 107,920 & 163,573 & $4,340,542$ & $6,578,906$ \\
\hline $75-79$ & 42.52 & 73,627 & 104,546 & $3,130,620$ & $4,445,296$ \\
\hline $80-84$ & 35.67 & 38,691 & 67,343 & $1,380,108$ & $2,402,125$ \\
\hline 85 & 29.53 & 24,534 & 53,313 & 724,489 & $1,574,333$ \\
\hline Total & & $3,626,296$ & $3,962,370$ & $42,758,139$ & $56,117,825$ \\
\hline \multicolumn{6}{|c|}{ Female population } \\
\hline $\begin{array}{l}\text { Age } \\
(y r)\end{array}$ & $\begin{array}{l}\text { 'per capita' } \\
\text { units of demand }\end{array}$ & $\begin{array}{l}\text { Population } \\
\text { projection (1999) }\end{array}$ & $\begin{array}{l}\text { Population projection } \\
\text { (2016) }\end{array}$ & $\begin{array}{l}\text { Estimated 'units of } \\
\text { demand' (1999) }\end{array}$ & $\begin{array}{l}\text { Estimated 'units of } \\
\text { demand' (2016) }\end{array}$ \\
\hline $0-4$ & 5.30 & 202,010 & 203,056 & $1,070,653$ & $1,076,197$ \\
\hline $5-9$ & 3.63 & 235,736 & 202,551 & 855,722 & 735,260 \\
\hline $10-14$ & 2.90 & 218,153 & 201,619 & 632,644 & 584,695 \\
\hline $15-19$ & 7.54 & 236,469 & 207,872 & $1,782,976$ & $1,567,355$ \\
\hline $20-24$ & 15.64 & 242,668 & 245,603 & $3,795,328$ & $3,841,231$ \\
\hline $25-29$ & 24.30 & 232,589 & 249,684 & $5,651,913$ & $6,067,321$ \\
\hline $30-34$ & 20.89 & 267,437 & 252,880 & $5,586,759$ & $5,282,663$ \\
\hline $35-39$ & 13.80 & 321,786 & 269,692 & $4,440,647$ & $3,721,750$ \\
\hline $40-44$ & 10.98 & 319,795 & 255,052 & $3,511,349$ & $2,800,471$ \\
\hline $45-49$ & 11.28 & 284,398 & 259,069 & $3,208,009$ & $2,922,298$ \\
\hline $50-54$ & 12.61 & 255,530 & 305,517 & $3,222,233$ & $3,852,569$ \\
\hline $55-59$ & 14.44 & 202,084 & 314,993 & $2,918,093$ & $4,548,499$ \\
\hline $60-64$ & 17.06 & 162,327 & 279,587 & $2,769,299$ & $4,769,754$ \\
\hline $65-69$ & 21.45 & 155,494 & 242,146 & $3,335,346$ & $5,194,032$ \\
\hline $70-74$ & 25.55 & 139,520 & 187,721 & $3,564,736$ & $4,796,272$ \\
\hline $75-79$ & 27.82 & 112,530 & 131,743 & $3,130,585$ & $3,665,090$ \\
\hline $80-84$ & 25.29 & 73,753 & 101,346 & $1,865,213$ & $2,563,040$ \\
\hline 85 & 21.52 & 66,935 & 136,954 & $1,440,441$ & $2,947,250$ \\
\hline Total & & $3,729,214$ & $4,047,085$ & $52,781,945$ & $60,935,748$ \\
\hline $\begin{array}{l}\text { Canadian } \\
\text { total }\end{array}$ & & $7,355,510$ & $7,506,950$ & $95,540,084$ & $117,053,573$ \\
\hline
\end{tabular}

Population estimates are taken from Statistics Canada data and the 'per capita' units of demand are calculated from RAMQ data (Figure) and used to calculate the projected demand for anesthesia services.

province, the projections were made separately for males and females in each of 18 age groups as shown for Quebec (Table I). A detailed description and data for the calculations of total 'units of demand' in each province are available in the full report. ${ }^{4}$

Table II summarizes the estimated number of FTE anesthesiologists that will be required to provide clinical services in each province (1999 and 2016). These estimates were calculated from the sum of the 'units of demand' for anesthesia services for all age/gender categories (from Statistics Canada) divided by the conversion factor for one FTE provider (175,000 units per FTE). 
TABLE II Calculated full-time equivalent (FTE) anesthesiologists for each province and the territories of Canada for both 1999 and 2016

\begin{tabular}{|c|c|c|c|c|c|c|c|}
\hline Province & $\begin{array}{l}1999 \\
\text { clinical } \\
\text { FTEs }\end{array}$ & $\begin{array}{l}1999 \\
\text { non-clinical } \\
\text { FTEs }\end{array}$ & $\begin{array}{l}\text { Total } \\
\text { FTEs needed in } \\
1999\end{array}$ & $\begin{array}{l}2016 \\
\text { clinical FTEs }\end{array}$ & $\begin{array}{l}\text { Adjusted * } \\
\text { no. clinical } \\
\text { FTEs }\end{array}$ & $\begin{array}{l}2016 \\
\text { non-clinical } \\
\text { FTEs }\end{array}$ & $\begin{array}{l}2016 \text { total } \\
\text { estimated * } \\
\text { FTEs }\end{array}$ \\
\hline Newfoundland & 40 & 4 & 44 & 41 & 43 & 6 & 49 \\
\hline PEI & 10 & 0 & 10 & 12 & 12 & 1 & 13 \\
\hline Nova Scotia & 70 & 10 & 80 & 81 & 81 & 14 & 95 \\
\hline New Brunswick & 56 & 3 & 59 & 63 & 63 & 4 & 67 \\
\hline Quebec & 546 & 60 & 606 & 669 & 650 & 80 & 730 \\
\hline Ontario & 852 & 108 & 960 & 1,164 & 1,155 & 150 & 1,305 \\
\hline Manitoba & 85 & 11 & 96 & 100 & 97 & 14 & 111 \\
\hline Saskatchewan & 76 & 7 & 83 & 88 & 85 & 9 & 94 \\
\hline Alberta & 207 & 22 & 229 & 272 & 294 & 31 & 325 \\
\hline British Columbia & 301 & 21 & 322 & 426 & 436 & 30 & 466 \\
\hline Territories & 6 & 0 & 6 & 9 & 9 & 1 & 10 \\
\hline Canada & 2,249 & 246 & 2,495 & 2,925 & 2,925 & 340 & 3,265 \\
\hline
\end{tabular}

*Denotes the "best estimate" of provincial requirements when considering the current inflows and outflows from clinical practice. These values are used for starting assessment of future supply of anesthesiologists (see reference 8).

Non-clinical anesthesiologists required (2016)

Based on the RCPSC survey, Table II summarizes the allocation of the 246 estimated non-clinical FTE anesthesiologists required in 1999.6 This estimate was made by extending these data to include all active certificants in the 1995 study and assuming a 50-hr work week. This led to an estimated need (in 1995) for Canada of 131 FTEs for academic activities and 96 FTEs for non-academic administrative activities. The total for 1995 (227) was adjusted to match increased clinical activities between 1995 and 1999 (assuming equivalent increase in non-clinical component) to produce the estimate of 246 FTEs for Canada. This total was then allocated by province. The academic component allocation was based on the number of anesthesiology residency positions and the 1998-99 research expenditures in anesthesiology (data from the Association of Canadian Medical Colleges). ${ }^{\mathrm{C}}$ The non- academic administrative component was based on the volume of clinical services in each province. The 2016 estimate of non-clinical FTEs (Table II) is 340 , a $30 \%$ increase from 1999 , matching the projected increase in clinical volumes.

\section{Projected need for anesthesiologists (1999-2016)}

In the report, ${ }^{4}$ Ryten made minor adjustments to the provincial distribution of the estimated FTEs required for clinical services in 2016. These are shown in Table II as "adjusted number of clinical FTEs" and can be considered the "best estimate of requirements for 2016". These FTE estimates are used as the starting point for reflection on future demand to examine whether current inflows into and outflows from practice are sufficient. The predicted FTE needs for 2016 total 3,265, increased from 2,495 in 1999 . The percentage increase in population and in the estimated demand for anesthesia services between 1999-2016 is shown for each province in Table III. The expected change in demand for anesthesia services can be separated into two components: that due to population growth and that due to demographic shifts. The component due to age/gender demographic changes is also shown in Table III. In Canada, population growth (using this Statistics Canada estimate) will increase by $17.9 \%$, whereas total demand for anesthesia services will increase by $29.1 \%$. The difference $(11.2 \%)$ is due to demographic changes.

\section{Discussion}

Canada has a shortage of anesthesiologists. ${ }^{1,6,7}$ Recently the shortage has resulted in operating room closures and a negative impact on the care of patients in need of surgery. This has given a sense of urgency to plan for future requirements. This article presents a unique approach to calculating the need for FTE anesthesiologists required to provide anesthesia services. The data identified the need for 3,265 FTE anesthesiologists. To complete a HRP model, these data need to be linked to an estimate of the future 'stock' of providers that will be available. This more comprehensive planning exercise is given in the second of the articles from the ACUDA study. ${ }^{4,8}$

The strengths of this planning model are: it quantifies relevant factors, such as the demography of the population; it measures the specific professional activities provided by the anesthesiologists; and it considers the demographics of specialty providers and the repercussions of changes in clinical practice norms. 
TABLE III Percentage change in demand for clinical anesthesia services (based on projections using the human resource planning model) for each province is shown as demand. The change in demand due to projected population change (based on one Statistics Canada model) and that due to the changing demographic composition of population (Dem Comp) are also shown.

\begin{tabular}{|c|c|c|}
\hline Province & Reason for change & $\%$ increase \\
\hline Newfoundland & $\begin{array}{l}\text { Population } \\
\text { Demand } \\
\text { Dem. comp. }\end{array}$ & $\begin{array}{l}-12.6 \% \\
+4.3 \% \\
+16.9 \%\end{array}$ \\
\hline $\begin{array}{l}\text { Prince } \\
\text { Edward Island }\end{array}$ & $\begin{array}{l}\text { Population } \\
\text { Demand } \\
\text { Dem. comp. }\end{array}$ & $\begin{array}{l}+1.2 \% \\
+14.4 \% \\
+13.2 \%\end{array}$ \\
\hline Nova Scotia & $\begin{array}{l}\text { Population } \\
\text { Demand } \\
\text { Dem. comp. }\end{array}$ & $\begin{array}{l}+1.3 \% \\
+15.6 \% \\
+14.3 \%\end{array}$ \\
\hline $\begin{array}{l}\text { New } \\
\text { Brunswick }\end{array}$ & $\begin{array}{l}\text { Population } \\
\text { Demand } \\
\text { Dem. comp. }\end{array}$ & $\begin{array}{l}-2.6 \% \\
+12.3 \% \\
+14.9 \%\end{array}$ \\
\hline Quebec & $\begin{array}{l}\text { Population } \\
\text { Demand } \\
\text { Dem. comp. }\end{array}$ & $\begin{array}{l}+8.9 \% \\
+22.5 \% \\
+13.6 \%\end{array}$ \\
\hline Ontario & $\begin{array}{l}\text { Population } \\
\text { Demand } \\
\text { Dem. comp. }\end{array}$ & $\begin{array}{l}+26.4 \% \\
+36.6 \% \\
+10.2 \%\end{array}$ \\
\hline Manitoba & $\begin{array}{l}\text { Population } \\
\text { Demand } \\
\text { Dem.comp. }\end{array}$ & $\begin{array}{l}+8.3 \% \\
+18.1 \% \\
+9.8 \%\end{array}$ \\
\hline Saskatchewan & $\begin{array}{l}\text { Population } \\
\text { Demand } \\
\text { Dem.comp. }\end{array}$ & $\begin{array}{l}+5.7 \% \\
+15.3 \% \\
+9.6 \%\end{array}$ \\
\hline Alberta & $\begin{array}{l}\text { Population } \\
\text { Demand } \\
\text { Dem. comp. }\end{array}$ & $\begin{array}{l}+15.8 \% \\
+31.7 \% \\
+15.9 \%\end{array}$ \\
\hline British Columbia & $\begin{array}{l}\text { Population } \\
\text { Demand } \\
\text { Dem. comp. }\end{array}$ & $\begin{array}{l}+26.6 \% \\
+41.5 \% \\
+11.9 \%\end{array}$ \\
\hline Territories & $\begin{array}{l}\text { Population } \\
\text { Demand } \\
\text { Dem. comp. }\end{array}$ & $\begin{array}{l}+30.8 \% \\
+50.7 \% \\
+19.9 \%\end{array}$ \\
\hline Canada & $\begin{array}{l}\text { Population } \\
\text { Demand } \\
\text { Dem.comp. }\end{array}$ & $\begin{array}{l}+17.9 \% \\
+29.1 \% \\
+11.2 \%\end{array}$ \\
\hline
\end{tabular}

The Figure shows age/gender differential rates of utilization of anesthesia services and illustrates the extent to which the aging population will determine the need for anesthesia services. Large variations in the 'per capita' expenditure on anesthesia services exist for different age/gender groups (Figure). Importantly, this study shows that there is an underlying regularity in the pattern of 'per capita' expenditures between provinces (Figure). If there was no regularity shown, the use of 'per capita' expenditure as a measure of future 'demand' for anesthesia services would be useless. The Figure demonstrates that this approach is possible, yet more experience will be required to assess its validity in all regions. For accurate projection of 'demand', it would be preferable to establish the 'per capita' expenditure on anesthesia services for each region independently. At present, complete data from other provinces are not available.

We chose to apply the Quebec 'per capita' expenditure on anesthesia services to other provinces because the RAMQ data collected all anesthesia services delivered in the province. Ontario's 'per capita' expenditure (Figure) represents only expenditures for services delivered by specialist anesthesiologists. It is notable that these are slightly higher than in Quebec and our projections for other provinces (Table II) may be a conservative estimate. The cause of this difference may be increased availability of anesthesia services in Ontario and/or increased remuneration for professional services. For the purpose of planning the workforce, inclusion of the work performed by all providers (e.g., family practitioner anesthesiologist) and nonclinical service is essential.

Some regional variation in the number of FTE anesthesiologists among the provinces is expected due to the fact that segments of the population with higher than average consumption of anesthesia services (Figure) are growing faster than segments that are lower users of anesthesia services. For example, in Newfoundland, the anticipated change in population is a decrease of $12.6 \%$ between 1999 and 2016 , however the calculations suggest an increase of $4.3 \%$ in 'demand' for anesthesia services (Table III). If demand parallelled population, the demand would be expected to decrease by $12.6 \%$. By inference, the difference between these two numbers (16.9\%) must be due to demographic (age/gender) composition. The need for regional planning is emphasized by the wide variations in the 'demand' shown between provinces (Table III). In provinces expected to experience rapid population growth (e.g., British Columbia and Ontario), the increases in 'demand' will be a result of both population growth and demographic change. Using this model, although some provinces will experience heavy population growth and some very little, all provinces will be faced with providing substantial increases in anesthesia services due to demographic change, largely aging of the population. 
The proposed methodology provides for changes in medical services utilized based on what anesthesiologists actually do. This flexibility can be accomplished through an ongoing analysis of the codes billed for services delivered and how amounts vary over time. This is possible because provincial Health Care systems have comprehensive billings data arising out of fee-for service payments. They provide Canada with an almost unique research tool compared with countries with multiple payer or salary systems. Another aspect of the flexibility of the model is its built-in provision for regular monitoring and updating of the data as they become available or when policy changes occur, such as a change in immigration targets.

As in all HRP planning, several assumptions were made. One major assumption in the model is that Quebec delivered all the anesthetic services required by the population in the base year (1998-99). Another assumption is the calculation of FTE equivalent, based on the Quebec data. We also made assumptions in calculating the non-clinical FTEs required (Table II). Recognizing these assumptions and limitations, it is important to emphasize that any HRP model is meant to "shape the future, not predict it". The calculations need to be repeated at intervals, and compared with current experience. This would provide for ongoing planning in a rational fashion. Repeating the calculations over time, would also allow for the refinement of predictions to account for new technologies and practice patterns. When Chairs of University Departments (ACUDA) examined the 1999 estimates of FTE providers (Table II), these were in accordance with the perceived need.

These data on the need for anesthesiologists form the basis of another report, which will focus on examining whether current inflows and outflows from practice are sufficient to ensure an adequate supply of anesthesiologists in the future. ${ }^{8}$ One of the most important conclusions of this study, is the feasibility of conducting specialty specific workforce planning in anesthesiology. The negative impact of planning from misguided HRP models is well-documented. ${ }^{2,9}$ The methods and model can be adapted for use by other specialties, and thus contribute to the quality of work done in physician workforce planning beyond the specialty of anesthesia. For this goal to be realized, the work must continue. Operating and implementing a physician workforceplanning model implies a long-term commitment, with dedicated resources and qualified personnel.

\section{Acknowledgements}

The ACUDA study was conducted by Ms. Eva Ryten (former Director of Research, Association of Canadian
Medical Colleges - retired) for the Management Committee of the Association of Canadian University Departments of Anesthesia (Chairs of all 16 Canadian University Departments). ACUDA and the Anesthesia Section of the Ontario Medical Association provided generous financial support for the project. We are grateful to the staff of the Department of Anesthesia of the Montreal Children's Hospital, and particularly to Ms. Victoria Kompogiannis for the review and analysis of billing codes in the development of the classification of anesthesia services by field of practice. In addition, our thanks go to the staff of the Service de Statistiques, Régie de l'assurance maladie du Québec, and in particular to Mme D. Labrie-Pelletier and Mr. J Barry, chef de service.

\section{References}

1 Donen N, King F, Reid D, Blackstock D. Canadian anesthesia physician resources: 1996 and beyond. Can J Anesth 1999; 46; 962-9.

2 Schubert A, Eckbout G, Cooperider T, Kuhel A. Evidence of a current and lasting national anesthesia personnel shortfall: scope and implications. Mayo Clin Proc 2001; 76: 995-1010.

3 Australian Institute of Health and Welfare. The anaesthetic workforce in Australia: supply, requirements and projections 1995-2006. Australian Medical Workforce Advisory Committee. January 1996.

4 Ryten E. A physician workforce planning model for the specialty of anesthesia: theoretical and practical considerations.

http://www.anesthesia.org/acuda/en/ryten.html

5 Abt Associates Inc. Prepared for the American Society of Anesthesiologists. Estimation of physician workforce requirements in anesthesiology. September 16, 1994.

6 Duncan PG. Anesthesia human resources in Canada (Editorial). Can J Anesth 2000; 47: 99-104.

7 Yang H, Byrick R, Donen N. Analysis of anesthesia physician resources: projected Ontario deficit in 2005. Can J Anesth 2000; 47: 179-84.

8 Craig DB, Byrick RJ, Carli F. A physician workorce planning model applied to Canadian anesthesiology: planning the future supply of anesthesiologists. Can J Anesth 2002; 49: 671-77.

9 Byrick RJ, Craig DB. Consequences of inadequate Canadian physician resource planning (Editorial). Can J Anesth 1999; 46: 913-8. 